\title{
Chronic Disease and Self-Injection: Ethnographic Investigations into the Patient Experience During Treatment
}

\author{
Michael Schiff · Shane Saunderson · Irina Mountian · Paul Hartley
}

Received: February 2, 2017 / Published online: September 27, 2017

(C) The Author(s) 2017. This article is an open access publication

\begin{abstract}
Introduction: Drug administration by self-injection provides an option to treat chronic inflammatory diseases such as rheumatoid arthritis (RA) and Crohn's disease (CD). However, a negative self-injection experience for patients may reduce patient adherence to the recommended treatment regimen. In this study, a holistic approach was used to identify common themes along the treatment pathway and at self-injection that, if changed, could improve patient experience and treatment outcomes.

Methods: Two ethnographic studies were conducted: Field Insights CODE (FI[CODE]) examined the treatment pathway within the context of the experience of living with RA or CD, and
\end{abstract}

Enhanced content To view enhanced content for this article go to http://www.medengine.com/Redeem/48FB F06031B761D6.

Electronic supplementary material The online version of this article (doi:10.1007/s40744-017-0080-4) contains supplementary material, which is available to authorized users.

M. Schiff $(\bowtie)$

University of Colorado School of Medicine, Denver, CO, USA

e-mail: michael.schiff@me.com

S. Saunderson · P. Hartley

Idea Couture, Toronto, Canada

I. Mountian

UCB Pharma, Brussels, Belgium
Injection Mission 2020 (IM2020) focused on the moment of self-injection. FI(CODE) used an open ethnographic approach to interview 62 patients and 10 healthcare professionals (HCPs) from the US and UK. IM2020 included a review of over 50 injection device design information sources from the sponsor, and interviews with 9 patients, $8 \mathrm{HCPs}$, and 5 medical device designers from the US, UK, Canada, and Japan.

Results: FI(CODE) identified suboptimal treatment practices along the treatment pathway in four key areas: treatment team communication, treatment choice, patient empowerment, and treatment delivery. Patients with more treatment options and greater disease understanding were less likely to struggle with the treatment process. IM2020 demonstrated that five related components influenced the self-injection experience: delivery process, emotional state, social perception, educational level, and ritualization of the self-injection process.

Conclusion: These analyses highlight several potential areas for improvement, including aligning the device more to patients' needs to improve treatment adherence, better accessibility to educational resources to increase patient disease understanding, and guidance to empower patients to develop an optimal personalized self-injection ritual.

Funding: UCB Pharma. 
Keywords: Biologics; Crohn's disease; DMARD; Self-injection; Rheumatoid arthritis

\section{PLAIN LANGUAGE SUMMARY}

Some medicines used to treat long-term conditions, such as rheumatoid arthritis or Crohn's disease, are injected under the skin. Often, patients can choose to inject medicines themselves (self-injection). This must be done correctly for the medicines to work properly. But, the training surrounding self-injection is uneven and often cannot address the fundamental problems facing all self-injecting patients.

What healthcare improvements could help patients self-inject successfully? To find out, we interviewed people living with rheumatoid arthritis or Crohn's disease, while others were doctors, nurses, and people who design injection devices.

We found four common problems in the overall healthcare that patients received:

1. There were communication problems between different healthcare professionals and between healthcare professionals and patients, for example about treatment options or goals.

2. Each level in the healthcare system (e.g., the nurse, doctor, hospital board, health insurance company) made decisions that limited how many treatment options were presented to patients for consideration.

3. Patients were not empowered, as they felt they lacked personal input, information, and control in treatment decisions.

4. Healthcare professionals focused on disease treatment but not patient experience; they did not fully explain how to perform injections (delivery), leaving patients to figure it out by trial and error.

In addition, five factors were identified that affected patients' experiences of self-injection:

1. Process of injection: minimal one-on-one instruction for self-injection left some patients anxious and more prone to mistakes.
2. Emotions: some patients were better than others at 'overriding' emotions (e.g., fear) when self-injecting.

3. Views on injections: there was negative social stigma around injections, but patients had greater trust in more technological, modern devices.

4. Education: doctors often failed to explain how to manage fear and anxiety.

5. Developing a ritual: patients with a ritualized routine for when, where, and how to self-inject were more confident.

If doctors and nurses can support patients by providing a greater choice of treatments and injection devices, and teaching more about self-injection, this could improve patients' experiences and allow medications to work better. Healthcare professionals should help patients to develop their own, optimal routine for self-injection.

\section{INTRODUCTION}

Chronic inflammatory diseases are estimated to affect $5-7 \%$ of the adult population and are a common cause of adult morbidity [1]. The introduction of biological therapies that target different inflammatory mediators such as tumor-necrosis factor (TNF) has been a major advance in the treatment of such disorders, including rheumatoid arthritis (RA) and Crohn's disease (CD) [2-4].

Subcutaneous injections are the most common route of administration for biologics and are often self-administered by patients. A number of different factors can influence the injection experience, including the type of device used to deliver the drug, the patient's clinical response to treatment, and the incidence of adverse reactions $[5,6]$. Importantly, these factors form only part of the self-injection experience. Education, training, and patient support have all been identified as factors that contribute to the success or failure of self-injection for both experienced and injection-naïve patients [7-9].

A poor self-injection experience can reduce patient adherence to the recommended 
treatment regimen and potentially impact treatment outcomes $[10,11]$. Nonadherence has been linked to increased morbidity and mortality, leading to higher healthcare costs and outpatient visits $[12,13]$. For example, nonadherence in CD patients has been associated with higher rates of hospitalization and surgery, more emergency room visits, longer hospital stays and higher healthcare costs [14-16]. While RA patients with higher persistence rates have been shown to have greater pharmacy costs, total non-pharmacy costs, including inpatient and outpatient visits and laboratory services, were lower than in patients with reduced persistence [17].

This qualitative ethnographic study provided a "holistic" examination of the patient experience at each stage of the treatment pathway to identify patient-reported difficulties inherent in the act of self-injecting biologics, and provides valuable information on services and devices that could support and improve the self-injection experience. Ethnography is commonly used by medical anthropologists and sociologists to examine the everyday lived experiences of patients and provide detailed insights into patients' treatment experience $[18,19]$. It relies on direct, participatory observation, engagement with patients over a period of several months, and detailed accounts of the patients' experiences, providing context to the experiential details of what was told, observed, and analyzed [20, 21]. As ethnographic research investigates patients and their experience directly, it can provide valuable insights that would be difficult to observe in more traditional, large-format, quantitative study environments [19].

\section{METHODS}

Two complimentary ethnographic research projects were conducted (summarized in Table 1). Field Insights CODE (FI[CODE]) focused on understanding the treatment experiences of patients with RA or CD at each step of the treatment pathway. Injection Mission 2020 (IM2020) focused on understanding the patient experience at the point of self-injection.

\section{FI(CODE) Research Project}

\section{Participant Eligibility Criteria}

FI(CODE) was conducted in the US (San Francisco, Chicago) and UK (London, Manchester) in September 2012. Participants included patients with RA or CD, and rheumatology or gastroenterology healthcare professionals (HCPs). Eligible patients had to be aged $\geq 18$ years, have a formal diagnosis of RA or $\mathrm{CD}$, and to be currently using a pre-filled syringe or autoinjector for self-administration of certolizumab pegol, etanercept, adalimumab, or golimumab. Use of intravenous infliximab administered to patients by a qualified HCP was also permitted. All patients had experienced past treatment failure and the use of more than one type of biologic. Patients were not eligible to participate if they were enrolled in an ongoing clinical trial.

All HCPs had between 4 and 30 years of experience in rheumatology or gastroenterology practice, either as a physician or as a certified specialist RA or CD nurse. Eligibility criteria stated that HCPs must have had appointments/consultations with $\geq 20$ patients within the previous month, and experience of prescribing either certolizumab pegol, etanercept, adalimumab, golimumab, or infliximab. HCPs could not participate if they worked for management consultancies, pharmaceutical or biotechnology companies, government medical oversight boards or medical commissions, medical device companies, marketing or business research agencies, or intellectual property law firms.

\section{Ethnographic Research Methods}

FI(CODE) used two ethnographic field methods: one-on-one interviews and group interviews. The one-on-one interviews ( $\geq 2 \mathrm{~h}$ in duration) were performed in-home for patients and in-office for HCPs, and used an adaptive methodology that enabled participants to discuss any topics they felt were relevant to their treatment experience, without imposing restrictions on the feedback obtained. The interviews were designed to explore and test a set of initial hypotheses concerning the 
Table 1 Summary of the FI(CODE) and IM2020 ethnographic research projects

\begin{tabular}{|c|c|c|}
\hline & FI(CODE) & IM2020 \\
\hline Full name & Field Insights CODE & Injection Mission 2020 \\
\hline Focus & Provided an overview of the treatment pathway & Focused on the actual process of self-injection \\
\hline Content & $\begin{array}{l}\text { Individual interviews and group interviews } \\
\text { examining the treatment pathway leading to } \\
\text { self-injection }\end{array}$ & $\begin{array}{l}\text { (1) A review of }>50 \text { sponsor internal information } \\
\text { sources regarding the design of an injection device } \\
\text { (2) Interviews with patients, HCPs, and device } \\
\text { designers to understand how injection devices } \\
\text { affect individual patients }\end{array}$ \\
\hline Location & $\begin{array}{l}\text { In-home with patients and in-office with HCPs, in } \\
\text { the US (San Francisco, Chicago) and UK } \\
\text { (London, Manchester) }\end{array}$ & $\begin{array}{l}\text { In-person and phone interviews with participants in } \\
\text { the US (San Francisco, Boston, Atlanta, New } \\
\text { York), UK (London), Canada (Toronto), and } \\
\text { Japan (Tokyo) }\end{array}$ \\
\hline \multirow[t]{14}{*}{ Methodology } & $\begin{array}{l}\text { In the US, interviews were conducted with: } \\
2 \text { RA patients } \\
2 \text { CD patients } \\
4 \text { rheumatology HCPs }\end{array}$ & $\begin{array}{l}\text { A variety of sponsor information sources were } \\
\text { reviewed, including reports, study materials and } \\
\text { disease overviews, and their perspectives on the } \\
\text { future of healthcare and devices were researched } \\
\text { and analyzed. }\end{array}$ \\
\hline & $\begin{array}{l}2 \text { gastroenterologists } \\
4 \text { RA patient focus groups }\end{array}$ & $\begin{array}{l}\text { Expert interviews were conducted with the } \\
\text { following: }\end{array}$ \\
\hline & $2 \mathrm{CD}$ patient focus groups & In the US: \\
\hline & In the UK, interviews were conducted with: & 7 patients \\
\hline & 4 RA patients & 2 HCPs \\
\hline & 4 rheumatology HCPs & 2 medical device designers \\
\hline & 6 RA patient focus groups & In the UK: \\
\hline & $\begin{array}{l}\text { Interviews used adaptive methodology (no set } \\
\text { questions/discussion guides). Ethnographic field } \\
\text { work used an open approach to avoid restricting } \\
\text { the feedback obtained. }\end{array}$ & $\begin{array}{l}2 \text { HCPs } \\
1 \text { medical device designer } \\
\text { In Canada: }\end{array}$ \\
\hline & Group interviews were conducted in the US and UK & 2 patients \\
\hline & In the US: & 4 HCPs \\
\hline & 4 labs with RA patients & 1 medical device designer \\
\hline & 2 labs with CD patients & In Japan: \\
\hline & In the UK: & 1 medical device designer \\
\hline & 6 labs with RA patients & \\
\hline
\end{tabular}

$R A$ rheumatoid arthritis, $C D$ Crohn's disease, $H C P$ healthcare professional 
association between self-injection and overall disease experience (examples of the hypotheses are provided in the methods included in the Electronic supplementary material, ESM). Themes covered included attitudes towards self-injection, successes and failures impacting adherence, barriers to successful injection, typical habits, and the role of pain in governing behavior.

Each patient group discussion $(2 \mathrm{~h}$ in duration, with either 6 or 3 participants) was moderated by an anthropologist. During the session, patients completed an exercise describing their treatment pathway (from diagnosis to self-injection). Patients then discussed their emotional and physical experience of treatment. The group interviews were conducted in a non-clinical and non-market research setting, to reduce any potential influence of the interview setting on the topics discussed.

\section{Data Analysis}

Participant feedback from the interviews was analyzed to identify common themes in the way people perceived living with their condition using a phenomenological hermeneutic approach [22]. This focused on the individual's personal, subjective experience and comprised three parts: firstly, an overarching examination of the sociocultural background of the individual, followed by a close examination of their actions and intentions in the context of their lived experience, and finally a rule development analysis to examine how action, intention, and sociocultural experience interact to identify successes and failures in self-injection and bridge gaps in the participants' experience [23].

Qualitative clustering analysis was used to identify homogeneous groups (clusters) of participant statements from the one-on-one interviews. Transcripts were coded and clustered by hand according to the following criteria: experience, belief, knowledge, education, sentiment, doxa (popular opinion) [24], acculturation (adoption of cultural traits or social patterns), deviation from clinical expectations, coping mechanisms, understanding of their disease based on discussions with friends/family, and basic demographic information. Statements that did not fit into any homogeneous cluster were analyzed using thematic analysis [25] to identify any distinctive connections with the common patient statements, and grouped accordingly.

Treatment pathway maps, sketched as part of the group interview process, were combined to create an agreed universal patient pathway. Common themes from the treatment pathway exercise conducted during the group interviews and statement clusters from the one-on-one interviews were used to develop a set of universal insight statements describing commonalities and differences in individual treatment experiences that explained how common events were shaped by emotion and action. These were placed chronologically along the treatment pathway, providing a detailed overview of a typical patient's treatment journey.

\section{IM2020 Research Project}

\section{Participant Eligibility Criteria}

IM2020 was conducted in the US (San Francisco, Boston, Atlanta, New York), UK (London), Canada (Toronto), and Japan (Tokyo) between February and March 2015. Participants included RA and CD patients, rheumatology and gastroenterology HCPs, and injection device design experts. Eligibility criteria for patients and HCPs were the same as described for FI(CODE). To be eligible to participate, all device designers had to have experience designing devices intended for medical use (requiring regulatory approval), specifically focusing on injection devices.

\section{Ethnographic Research Methods}

IM2020 focused on patient experience during the process of self-injection using two approaches. The first approach was a review of over 50 information sources (provided by the study sponsor) examining the design and usage of an injection device. Information sources included but were not limited to insights reports, market scans, human factors studies, survey research, field videos, and patient profiles. These sources provided background information to develop interview questions and a framework for the field research. 
The second approach was a series of expert interviews with the aim of understanding how the design of injection devices affects individual patients. Each interview was $1-2 \mathrm{~h}$ in duration, and was conducted by a researcher over the telephone or in person. Four patients interviewed in FI(CODE) were re-interviewed as part of the IM2020 project. The remaining interviewees were recruited through a combination of third-party recruitment agencies, personal networks, and direct contact using the same eligibility criteria as FI(CODE).

\section{Data Analysis}

Feedback from the IM2020 interviews was analyzed using the same clustering methodology as described for FI(CODE) to look for common statements or topics and their impact on the self-injection experience. The statement clusters were used to develop a number of insight statements. These were grouped into subcategories and used to develop a set of universal statements describing the self-injection experience.

\section{Compliance with Ethics Guidelines}

All procedures followed were in accordance with the ethical standards of the responsible committee on human experimentation (institutional and national) and with the Helsinki Declaration of 1964, as revised in 2013. Informed consent was obtained from all patients before they were included in the study.

\section{RESULTS}

\section{FI(CODE) Participants}

FI(CODE) consisted of 8 patient in-home interviews, $10 \mathrm{HCP}$ in-office interviews, and 12 patient group interviews (involving 54 patients). In the US, interviews were conducted with 2 RA patients, 2 CD patients, 4 rheumatologists ( 2 doctors and 2 nurses), 4 gastroenterologists, 4 RA patient groups and 2 CD groups (6 participants in each patient group). In
Table 2 Patient baseline demographics

\begin{tabular}{ll}
\hline Category & ${\text { \% } \text { Patients }^{\mathbf{a}}}^{\text {Age, years }}$ \\
$18-25$ & - \\
$26-35$ & 34 \\
$36-55$ & 40 \\
$56-65$ & 23 \\
$66-70$ & 3 \\
Time since diagnosis, years & \\
$<5$ & 80 \\
$5-20$ & 20 \\
Time on biologic, years & \\
$<1$ & 2 \\
$1-<3$ & 48 \\
$\geq 3-<5$ & 40 \\
$\geq 5$ & 10
\end{tabular}

Self-injection experience, years

$$
\begin{array}{ll}
1-<3 & 50 \\
\geq 3-<5 & 40 \\
\geq 5 & 10
\end{array}
$$

a Based on screening data from the 62 patients in the FI(CODE) study

the UK, interviews were conducted with 4 RA patients, 4 rheumatologists, and 6 RA groups ( 3 participants in each group).

A summary of patient baseline demographics is presented in Table 2 . The majority of the patients had been diagnosed within the past 5 years and had been treated with a biologic for $\geq 1$ year. All patients had $\geq 1$ year of self-injection experience, with $10 \%$ of patients having $>5$ years of experience.

Feedback from interviews highlighted the difficulties involved in uncovering the full experience of self-injection by patient observation (an alternative ethnographic procedure) [26], as many patients viewed self-injection as a private act (Table 3, Q1-Q3). Over the course of the one-on-one interviews it became clear that, while self-injection is common for patients 
Table 3 Statements from FI(CODE) participants

\begin{tabular}{|c|c|c|}
\hline $\begin{array}{l}\text { Quote } \\
\text { identifier }\end{array}$ & Participant & Participant statement \\
\hline $\mathrm{Q} 1$ & Patient & $\begin{array}{l}\text { "I always wait for everyone to } \\
\text { leave before I start" }\end{array}$ \\
\hline Q2 & Patient & $\begin{array}{l}\text { "I never do it in front of my } \\
\text { family, or even my husband. I } \\
\text { always find a calm, dark, and } \\
\text { quiet space to finally get down } \\
\text { to it" }\end{array}$ \\
\hline Q3 & Patient & $\begin{array}{l}\text { "The bathroom is the only place } \\
\text { in the house where I can do } \\
\text { it... There is a lock on the } \\
\text { door" }\end{array}$ \\
\hline Q4 & Patient & $\begin{array}{l}\text { "I failed on everything else, and } \\
\text { the pain was still there... I } \\
\text { remember being very angry } \\
\text { with my doctor" }\end{array}$ \\
\hline Q5 & Patient & $\begin{array}{l}\text { "I went [to the doctor] to be } \\
\text { treated, and I wasn't prepared } \\
\text { for the fact that the drugs } \\
\text { wouldn't work at first. Only } \\
\text { now do I understand" }\end{array}$ \\
\hline Q6 & Patient & $\begin{array}{l}\text { "The methotrexate made me } \\
\text { really sick, and I kept thinking } \\
\text { that this would never get } \\
\text { better. I had to keep going } \\
\text { however, because I needed to } \\
\text { prove that it didn't work } \\
\text { before I got a biologic" }\end{array}$ \\
\hline Q7 & Doctor & $\begin{array}{l}\text { "Patients have to progress } \\
\text { through the established } \\
\text { guidelines. When someone } \\
\text { arrives with a clearly severe } \\
\text { case, we still have to put them } \\
\text { on methotrexate" }\end{array}$ \\
\hline Q8 & Patient & $\begin{array}{l}\text { "I love my Humira, it changed } \\
\text { my life. The pain basically left } \\
\text { and I was able to get back to } \\
\text { the way I felt before" }\end{array}$ \\
\hline Q9 & Patient & $\begin{array}{l}\text { “I love my biologic, but I hate } \\
\text { self-injecting. I hate it more } \\
\text { than everything" }\end{array}$ \\
\hline Q10 & Patient & $\begin{array}{l}\text { "The worst part about this entire } \\
\text { experience is that damn } \\
\text { needle. It burns like fire" }\end{array}$ \\
\hline Q11 & Patient & $\begin{array}{l}\text { "I had to go back to the first-line } \\
\text { treatments because I just could } \\
\text { not use the needle pen } \\
\text { [self-injector]" }\end{array}$ \\
\hline
\end{tabular}

treated with biologics, it is an idiosyncratic experience grounded in fear and the desire to alleviate pain.

All RA and CD patients had experienced severe disease conditions and reported a precipitous loss of quality of life as their disease activity increased. Most described a wide variety of bodily pain and discomfort, compounded by the social discomforts of losing their mobility or what they called "their life as it was before." Often, this meant that patients' daily activities were affected by their condition and they were unable to be as socially or physically active as they were previously. This was accompanied by a feeling of disconnection from their previous disease-free lives, resulting in feelings of anxiety and depression.

\section{Prior Treatment Experiences}

Many FI(CODE) patients reported initial negative experiences post-diagnosis. In the US and UK, clinical guidelines dictate that patients must be treated with first-line medications such as corticosteroids and methotrexate before biologic therapy is considered [27, 28]. First-line therapy was identified as the point at which the patient experience of treatment often diverged from clinical expectations. HCPs view first-line therapy as a necessary first step in the treatment pathway, with success or failure determining if a patient should be offered a biologic. However, because HCPs rarely convey the treatment pathway to their patients, who are often uninformed about their condition and clinical options, this experience is almost exclusively perceived as one of failure and frustration (Table 3, Q4-Q6). Our results suggested that the initial frustration of first-line treatment failure was rarely addressed by HCPs who continued to see it as a part of the treatment process (Table 3 , Q7). This experience sets the stage for how patients then viewed their subsequent treatment, adding a heightened feeling of anxiety. However, once on biologic therapy, patients often reported a drastic improvement in their outlook on life (Table 3, Q8).

The "time before" is a concept that arose in over $75 \%$ of the interviews, and reveals the basis of the evaluative criteria patients used to gauge treatment success. The study participants 
looked to their experiential past to identify a time that was free of pain, discomfort, reminders of poor health, social isolation, and disease activity. This represents an important cluster of concepts that contextualize self-injection. While the self-injection procedure is tolerated because it delivers therapeutic benefits, the act itself introduces a new pain-the pain of the injection-that works against the patient's desire to be "like before," and becomes an ambivalent experience (Table 3, Q9-Q11).

\section{FI(CODE) Qualitative Insights into the Treatment Pathway}

One-on-one interviews, group interviews, and observations from $\mathrm{FI}(\mathrm{CODE})$ were used to develop a typical patient treatment pathway (Fig. 1). Insight statements, applicable to the different stages of this treatment pathway, were developed from discussions with patients and HCPs and revealed suboptimal treatment practices throughout the patient journey.

\section{Treatment Team Communication}

Interviews with individual members of the treatment team (patient, doctor, nurse) revealed communication barriers between team members. This was often caused by the division of labor among different HCPs (i.e., doctor, nurse), which restricted the flow of information such that individual HCPs were unaware of the pressures facing other members of the team (Table 4, Q1-Q2). Although these pressures did not directly involve the patient, they could negatively influence the way the patient perceived their care (Table 4, Q3).

Communication barriers also existed between the HCP team and the patient. For example, during consultation, a primary objective for the HCP was to explain the patient's diagnosis, while the patient preferred to understand the impact of the disease on their life. This was particularly evident during treatment selection, where patients rarely understood what was happening to them and why they were prescribed specific therapies (Table 4, Q4). Often, a number of treatment failures were required before patients became aware of the available treatment options (Table 4, Q5-Q7). A common reason cited by HCPs for the suboptimal communication was their workload, which reduced the available time to discuss their patient's disease in detail (Table 4, Q8).

Communication between the HCP and patient influenced patient expectations and their definitions of treatment success, influencing how they perceived treatment outcomes. Without establishing appropriate expectations at treatment initiation, patients often had difficulty evaluating treatment success, leading to variability in how patients reported their treatment outcomes, despite similar levels of disease improvement (Table 4, Q9-Q10).

\section{Patient Empowerment}

The interviews highlighted the patients' desire to be informed about their disease and play an active role in decisions guiding their treatment plans. The competing demands on HCP time limited their ability to discuss the disease and explain treatment decisions with patients. However, without active involvement, patients sometimes experimented with alternative treatment options, which could interfere in the treatment process and negatively affect treatment outcomes (Table 4, Q11-Q12). Without HCP guidance, patients searched for information from other sources (Table 4, Q13); however, as patients were rarely knowledgeable enough to differentiate between reputable and inaccurate sources, there was a risk of accessing incorrect information. For HCPs to successfully guide the patient to educate themselves about their disease, they required sufficient understanding of the patient experience and needs, which was often lacking due to the communication barriers described above.

Patients' main motivation was to alleviate the pain of their condition (Table 4, Q14-Q15) and they tended to underestimate the impact of long-term physical damage caused by the disease. If there was not a rapid reduction in pain, patients would consider their treatment a failure and would want to move to an alternative therapy. Patients also reported that the pain was not only physical but emotional and socialcaused by the functional disabilities of the disease. 


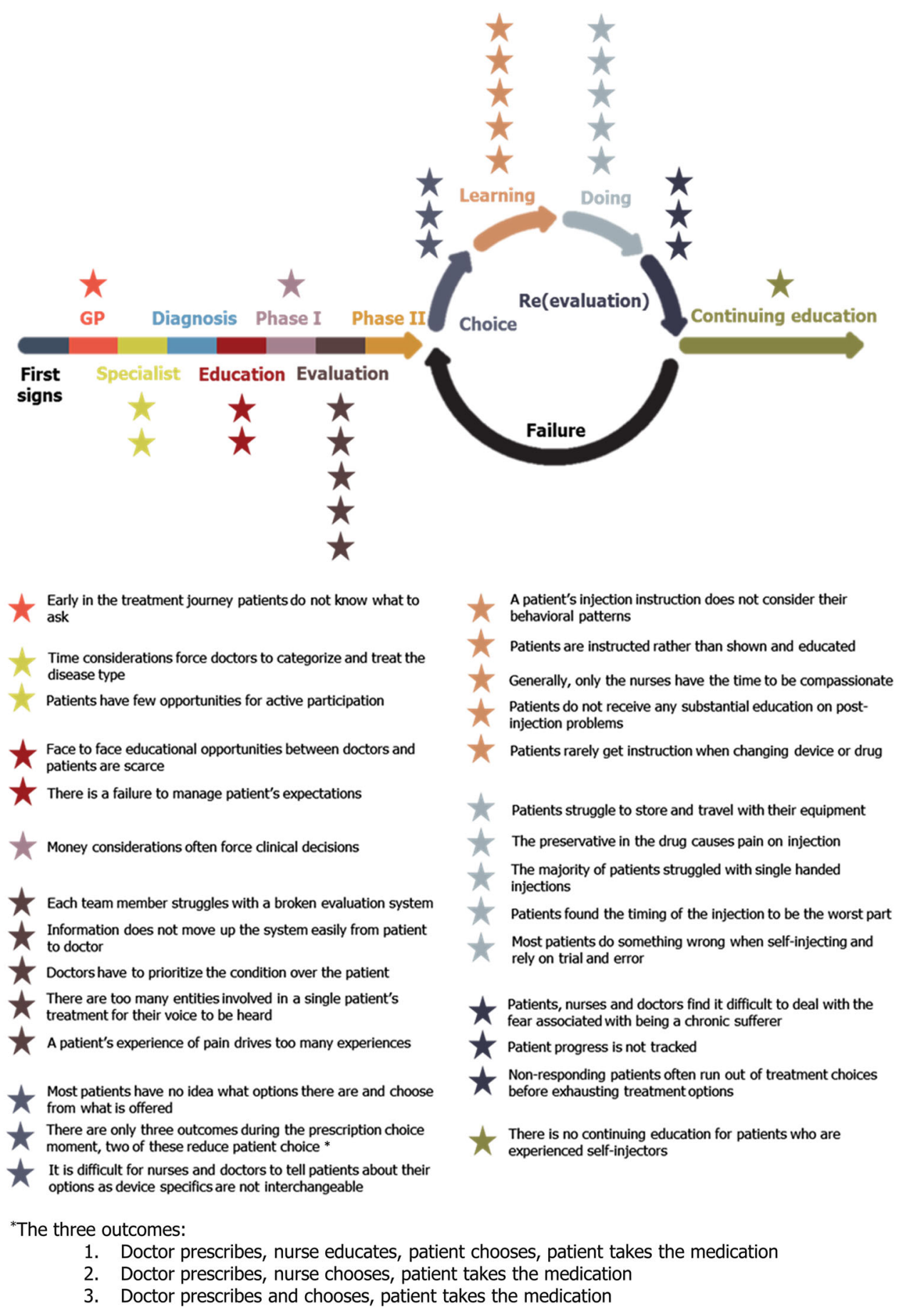

Fig. 1 The patient pathway and associated insight statements developed using FI(CODE) 
Table 4 Participant statements providing qualitative insights into self-injection from FI(CODE)

\begin{tabular}{|c|c|c|}
\hline $\begin{array}{l}\text { Quote } \\
\text { identifier }\end{array}$ & Participant & Participant statement \\
\hline \multicolumn{3}{|c|}{ Treatment team communication } \\
\hline Q1 & Doctor & $\begin{array}{l}\text { "My concern is to manage the patient's condition. If they are struggling with the injection I } \\
\text { have to let the nurse deal with that more directly" }\end{array}$ \\
\hline Q2 & $\begin{array}{l}\text { Nurse } \\
\text { Practitioner }\end{array}$ & $\begin{array}{l}\text { "We have nearly } 6,000 \text { patients in my practice. I have to treat them as cases because I don't } \\
\text { have time to deal with everything" }\end{array}$ \\
\hline Q3 & Patient & "I don't feel like my doctor treats me like a person. He just cares about my RA" \\
\hline Q4 & Patient & $\begin{array}{l}\text { "I did not even know about the other drugs until you told me. My doctor just completes his } \\
\text { checklist and refills my prescription" }\end{array}$ \\
\hline Q5 & Patient & $\begin{array}{l}\text { "I have had this since I was a child and taken everything there is to take. Because of this I've } \\
\text { had the time to learn about it all. I feel bad for people who are just starting" }\end{array}$ \\
\hline Q6 & Patient & $\begin{array}{l}\text { "Because I can't do it they put me on a different medication. When I couldn't do that one } \\
\text { they put me on Remicade so I can just have it as an IV drip. Why didn't they tell me about } \\
\text { that in the first place? I would have chosen that one" }\end{array}$ \\
\hline Q7 & Patient & $\begin{array}{l}\text { "I've tried everything and nothing has worked... One even gave me a stroke... I know about } \\
\text { it all” }\end{array}$ \\
\hline Q8 & Doctor & "We have seven minutes to visit with a patient. I cannot tell them everything at once" \\
\hline Q9 & Patient & $\begin{array}{l}\text { "I've been on Humira for a year now and I'm back to running half marathons. I think it is } \\
\text { working" }\end{array}$ \\
\hline Q10 & Patient & $\begin{array}{l}\text { "Things are going great. My pain has basically gone away. If it weren't for the three-day rash I } \\
\text { have after I'm injecting and the huge egg that shows up everything would be perfect" }\end{array}$ \\
\hline \multicolumn{3}{|c|}{ Patient empowerment } \\
\hline Q11 & Patient & $\begin{array}{l}\text { "I'm not taking this medication anymore and I haven't told my doctor because he won't } \\
\text { agree with me" }\end{array}$ \\
\hline Q12 & Doctor & $\begin{array}{l}\text { "Patients often turn to the alternative stuff like Chinese medicine because once they are on } \\
\text { the biologic there is nothing for them to do" }\end{array}$ \\
\hline Q13 & Patient & $\begin{array}{l}\text { "I had to search for information about what to do if anything went wrong by myself. How } \\
\text { can we be expected to do this alone when they only tell us how to use the stupid pen?" }\end{array}$ \\
\hline Q14 & Patient & "I'm not the kind of guy to try this stuff, but if it makes the pain go away, I'll do it" \\
\hline Q15 & Patient & $\begin{array}{l}\text { "If it isn't working or I forget to take it, I'm in pain... We have pain all the time. The point } \\
\text { is to make it go away" }\end{array}$ \\
\hline \multicolumn{3}{|c|}{ Treatment choice } \\
\hline Q16 & Doctor & $\begin{array}{l}\text { "The insurance companies have a lot to say about which we should choose first. We have to } \\
\text { work hard to do anything outside of what they suggest. So I avoid this problem whenever I } \\
\text { can" }\end{array}$ \\
\hline
\end{tabular}


Table 4 continued

\begin{tabular}{|c|c|c|}
\hline $\begin{array}{l}\text { Quote } \\
\text { identifier }\end{array}$ & Participant & Participant statement \\
\hline Q17 & Nurse & $\begin{array}{l}\text { "The doctor tells us which ones to offer the patient and we help them decide... Yes, we are } \\
\text { rare" }\end{array}$ \\
\hline Q18 & Patient & $\begin{array}{l}\text { "Yes my doctor let me have a lot of choice. He told me about both of the biologic } \\
\text { medications [Humira and Enbrel] and let me choose between them" }\end{array}$ \\
\hline Q19 & Patient & "I know more about all of this than the doctors do... No, I've never heard of Cimzia" \\
\hline Q20 & Patient & $\begin{array}{l}\text { "My doctor put in a request for every one of them. The first one that came back was the one } \\
\text { I started with" }\end{array}$ \\
\hline Q21 & Doctor & $\begin{array}{l}\text { "Once a patient fails on the first biologic, there is usually a set pathway for what happens } \\
\text { next" }\end{array}$ \\
\hline Q22 & Patient & "I was never told I had any options. They just gave me a prescription and told me to get to it" \\
\hline Q23 & Patient & "It is always a struggle. I have to choose to pay for this expensive drug or sit around in pain" \\
\hline Q24 & Patient & "I want to avoid taking another biologic until I can get the other knee replaced" \\
\hline \multicolumn{3}{|c|}{ Treatment delivery and patient rituals } \\
\hline Q25 & Patient & $\begin{array}{l}\text { "I take blood from other people every day but I can't handle the needle. I'm too scared to do } \\
\text { it" }\end{array}$ \\
\hline Q26 & Patient & "The worst part for me is how depressed it makes me" \\
\hline Q27 & Patient & "The equipment reminds me that I'm sick" \\
\hline Q28 & Nurse & $\begin{array}{l}\text { "We can only help them so much. They have to do it themselves. We're here if they have } \\
\text { questions though" }\end{array}$ \\
\hline Q29 & Patient & $\begin{array}{l}\text { "My doctor gave me a prescription for Humira and said nothing else. I had to work it out for } \\
\text { myself" }\end{array}$ \\
\hline Q30 & Patient & $\begin{array}{l}\text { "I pour myself some wine, turn the lights down, and sit there until the wine is gone. Then I } \\
\text { smoke a cigarette. Once that is done I know it is time to go" }\end{array}$ \\
\hline Q31 & Patient & $\begin{array}{l}\text { "I do it in the same chair at the same time. I put the reminder in my phone so I know I have } \\
\text { to do it" }\end{array}$ \\
\hline Q32 & Patient & "I just open the fridge, pull it out and go. There is no point in hanging about" \\
\hline Q33 & Patient & $\begin{array}{l}\text { "I have to find a quiet space to go, drink a glass of wine, hold it in my hands for a while just } \\
\text { to work up the guts to put it in my leg" }\end{array}$ \\
\hline Q34 & Patient & $\begin{array}{l}\text { "I always do it the same way, on the same day... I need to focus on getting over my distaste } \\
\text { of the whole thing" }\end{array}$ \\
\hline Q35 & Patient & $\begin{array}{l}\text { "I was given a prescription like it was penicillin or something. I went to the Wallgreens and } \\
\text { they gave me this box. I asked them what I'm supposed to do with it, and they helped a } \\
\text { bit. But they didn't know. I had to just go home to figure it out" }\end{array}$ \\
\hline
\end{tabular}




\section{Treatment Choice}

Generally, the number of treatment options available was determined by a combination of the structure of the country's healthcare system and the patient's personal circumstances. Patients receiving private healthcare in the US often had more than one treatment option, whereas options were limited for those receiving state-funded medical care. In the UK, there was greater treatment homogeneity, but the role of local clinical care commissioning groups resulted in regional differences.

The structure of the reimbursement and healthcare management systems in each country prevented HCPs from providing maximal treatment choice. Multiple healthcare system levels (i.e., nurse, doctor, primary care trust board, health insurance company) created a "reductive cascade" that limited the number of treatment options available to patients (Table 4, Q16-Q17). This was rarely recognized by patients, as they had limited insight into the available treatment options (Table 4, Q18-Q20).

Therapeutic choice did not improve following failure of the first biologic as the treatment pathway that was followed was often predefined (Table 4, Q21-Q22). In countries where the cost of healthcare is charged at the time of treatment, for example the US, patients' decisions were often directed by their financial circumstances, which could prevent patients trying alternative therapies when one failed (Table 4, Q23-Q24).

\section{Treatment Delivery and Patient Self-injection Rituals}

The role HCPs play within healthcare systems dictates that they focus on disease activity, rather than the emotional aspects of patients' treatment experience. Following diagnosis and treatment selection, biologic administration by self-injection was a major concern for patients (Table 4, Q25-Q27). Successful self-injection was dependent on a number of factors, the first of which was the guidance patients received from HCPs on treatment administration. Detailed user instructions required an investment of HCP time, a resource limited by workload and medical practice experience (Table 4, Q28). Patients without the necessary guidance were often left to learn using the manufacturer's instructions for use and trial and error (Table 4, Q29).

Many patients reported mentally preparing themselves for the moment of self-injection. Where possible, patients would inject in the same place using a set routine (Table 4, Q30-Q32). Patients ritualized the self-injection event in different ways. However, all patient rituals served to mitigate the fear and anxiety, and to alleviate the pain of self-injection (Table 4, Q33-Q34). For many patients this involved sequestering themselves away from public view, finding a way to locate an injection site that was relatively free from pain, coming to terms with the device, and ensuring they used it correctly. The patients often spent time working up the courage to initiate the injection. In the final moments, they prepared the injection site, oriented the device for what they considered to be optimal delivery, and injected. Following self-injection, patients often engaged in a number of pain reduction actions including massaging the area, pushing down what one called "the skin bubble", drinking alcohol to steady nerves, or putting ice on the site to eliminate bruising.

Injection training for patients was varied and for many patients was unavailable (Table 4, Q35); in this study, 25/62 patients reported receiving no training at all. When training was available, it focused on educating people about correct technique and the different devices available. HCPs often provided an overview of the manufacturer's recommendations for device management, dealing with device failures, and intended use. Patients relied on the instructions for use, and trial and error to learn how to recognize self-injection success or failure and how to alleviate injection pain. This resulted in a set of highly idiosyncratic injection rituals that often habitualized use errors. Several patients reported significant problems with their self-injections, such as bruising, "skin bubbles," intense pain at the injection site, injecting into their fingers or thumbs, shallow 
injections that resulted in drug leakage from the site of injection, and discomfort for several days post-injection.

\section{Qualitative Insights into Self-Injection from IM2020}

Overall, 22 experts were interviewed as part of the IM2020 project: 9 injection-experienced patients ( 7 in US, 2 in Canada), 8 HCPs ( 2 in US, 2 in UK, 4 in Canada), and 5 medical device designers ( 2 in US, 1 in UK, 1 in Canada, 1 in Japan).

Key insights into the moment of self-injection emerged from $>30 \mathrm{~h}$ of interviews. These insights were grouped and used to develop a framework, demonstrating that the act of self-injection is contextualized and controlled by a number of larger considerations beyond the moment of injection (Table S1 in the ESM). Examples of these considerations include reports of injection use (both medical and illicit use) in the media, misunderstanding of injection devices and their use, day-to-day differences in an individual's life, and the patient's mental state. Using clustering analysis, these considerations were organized into a set of five universal statements-delivery process, emotional and experiential state, social perception, educational level, and ritual development-which described the moment of self-injection.

\section{Delivery Process}

Most injection devices are designed with a similar, universal use in mind. As the self-injection process can vary between patients, and even between a patient's individual injections, this was not optimal. For example, hand dexterity and strength are closely related to disease progression and may differ significantly between patients.

The results from FI(CODE) identified insufficient education as a cause of improper injection technique. Similar observations were made in IM2020; insufficient education and feedback to validate successful use of the injection device led many patients to develop and habitualize improper injection technique or processes.
Before self-injection, patients reported high levels of stress and overlooked critical steps needed to successfully self-inject (Table 5, Q1-Q3).

\section{Emotional and Experiential State}

Patients viewed using a needle as an unnatural, transgressive act. Patients looked for comfort, assurance, and guidance from others (doctors, nurses, other patients) to help them self-inject. Patients did not consider the device part of the therapy, drawing a distinction between the drug, which helps them, and the device, which hurts them. Different patients reported a preference for different levels of control over self-injection. The emotional aspects associated with self-injection were often lost during the design process, and self-injection devices often failed to accommodate the more intangible aspects of the therapeutic experience, for example ritual development (Table 5, Q4-Q5).

\section{Social Perception}

Social and cultural perceptions and experiences of the patient had an impact on self-injection. Patients associated needles with fear (e.g., illicit drug use or with being unwell) and found it difficult to speak positively about the injection. These associations often resulted in patients fearing the injection device more than the pain of self-injection. Because of their familiarity with consumer electronics, patients expressed greater confidence with the use of technologized injection devices (Table 5, Q6-Q8).

\section{Educational Level}

Patients learnt to self-inject over time through trial and error with pain and body reactions as their primary feedback. The interviews conducted in IM2020 supported the conclusions reached in $\mathrm{FI}(\mathrm{CODE})$, i.e., that $\mathrm{HCP}$ training varied and focused on teaching patients the minimal mechanics of self-injection. Patients were not taught how to troubleshoot if they ran into difficulty while self-injecting, and HCPs had little understanding of how patients managed the fear and anxiety of self-injection (Table 5, Q9-Q11). 
Table 5 Participant statements providing qualitative insights into self-injection from IM2020

\begin{tabular}{|c|c|c|}
\hline $\begin{array}{l}\text { Quote } \\
\text { identifier }\end{array}$ & Participant & Participant statement \\
\hline \multicolumn{3}{|c|}{ Delivery process } \\
\hline Q1 & Patient & $\begin{array}{l}\text { "Yes, I was taught to use the pen in the office, but I forgot it all the moment the adrenaline was } \\
\text { running. I had to work it out for myself in the end" }\end{array}$ \\
\hline Q2 & Patient & $\begin{array}{l}\text { "I was taught to use this horrid thing by my friend Olga. She is not fussed about it and she } \\
\text { came over to my house to help me until I could do it myself" }\end{array}$ \\
\hline Q3 & Patient & $\begin{array}{l}\text { "I learned by trial and error, and there were some major errors. I was never told how to } \\
\text { understand if I did it properly. I've been doing it for years now, and only recently have I felt } \\
\text { secure" }\end{array}$ \\
\hline
\end{tabular}

Emotional and experiential state

Q4 Patient 'I've told you this before, I have to really work myself up into it. The wine helps, but that is not that healthy. I am still scared stiff"

Q5 Patient "This thing is so clinical, it does not suggest that it is safe to use. I have a little shock every time I see it. That might be the worst part of the entire event-just opening the package”

Social perception

Q6 Patient 'It's a needle. It isn't safe is it?... It is the kind of thing that you spend your life trying to avoid. Now it is part of my life. I still hate it"

Q7 Patient "I just wish it could tell me more about what is going on. My phone and my Fitbit can tell me quite a lot. Why are these devices so dumb?"

Q8 Patient "The device reminds me that I'm sick. I hate it for that... The injection itself is fine. Once I got used to it, it became fine"

Educational level
Q9 Patient
"I told my doctor about the pain, and he just said it was common. He suggested that I take the training course again. I had to figure out that it was the angle I was injecting at that was the problem by myself
Q10 Patient "I gave up with the instructions because I just cannot inject into my stomach. I just do it in the same leg and don't tell my doctor about it"
Q11 Patient "I had so many problems at the beginning, but I didn't want to ask about it. I was embarrassed... What? No, no one told me how to, what's the word, evaluate or triage my injection. I just pat the bubble down now instead of leaving it there”

Ritual development

\begin{tabular}{|c|c|c|}
\hline Q12 & Patient & $\begin{array}{l}\text { "I always do it at the same time of day, in the same place, and alone. That way I just have to } \\
\text { look at the clock on my injection day and I know what I need to do... I sit down, take the } \\
\text { caps off, find a place that feels safe, take a deep breath and then go. It hasn't gotten easier, } \\
\text { but it's less painful now" }\end{array}$ \\
\hline Q13 & Patient & $\begin{array}{l}\text { "I'm quick, but you're right, it is always the same. I just open the fridge, pull it out and get on } \\
\text { with it. That way I don't have to think about it anymore" }\end{array}$ \\
\hline
\end{tabular}


Table 5 continued

\begin{tabular}{lll}
\hline $\begin{array}{l}\text { Quote } \\
\text { identifier }\end{array}$ & Participant & Participant statement \\
\hline Q14 & Patient & "It takes me about two days to work up the courage. I try to leave it off until I start to hurt. \\
& $\begin{array}{l}\text { When the pain arrives, I know I have to inject and I spend a day or so circling the fridge... } \\
\text { Once I have the courage, I have to just hold it in my hands for a few minutes to get over the } \\
\text { feeling of wanting to run away. Sometimes I have to have someone with me, but I prefer } \\
\text { doing it alone" }\end{array}$ \\
\hline
\end{tabular}

\section{Ritual Development}

As identified in FI(CODE), patients developed injection rituals to mitigate the fear and anxiety of self-injection. This was further examined during patient interviews in IM2020, revealing a number of additional insights. Rituals were a way to "control" the injection and to allow patients to make the experience easier from a social and emotional perspective. Patients preferred to inject in the same location, at the same time, using the same methodology. The moment of self-injection was a small component of the patient's ritual, which could begin days before and end hours or days after the injection. Ritual development was largely beneficial for the patient; for example, patients who had developed a ritual reported more confidence during self-injection. Despite the benefits of ritual development, HCPs focused on the mechanics of injection and did not discuss ritual development (Table 5, Q12-Q13).

\section{DISCUSSION}

This study reports the findings from two ethnographic research projects, FI(CODE) and IM2020, which explored the entire patient experience of self-injection from a holistic point of view. The factors identified have the potential to influence treatment outcomes in RA and $\mathrm{CD}$, where self-administered injection is a common treatment option for patients.

Qualitative ethnographic methods provide important insights into a patient's treatment pathway that could be missed in larger, quantitative real-world studies. For example, quantitative analyses examining patient self-injection compliance will effectively describe when and how often patients become noncompliant; however, they do not focus on reasons for noncompliance. Qualitative approaches enable researchers to investigate patients' experiences and feelings to examine the reasons behind their actions. By observing and discussing treatment experience with patients directly in a real-world setting, the lived experience of patient self-injection can be closely examined [19].

Qualitative studies have been used successfully in a number of studies to provide insights into patient behavior. Patients' desire for empowerment was previously reported in an ethnographic study highlighting contrasts in patient- and physician-reported opinions of living with RA [29]. A study of opinions on long-acting injectable antipsychotic therapy for schizophrenia used ethnographic information to uncover how healthcare providers feared that greater patient involvement could damage the therapeutic relationship [30].

The FI(CODE) and IM2020 projects used an adaptive ethnographic methodology grounded in contemporary design anthropology. This created a novel, interviewee-focused environment, where the interview discussions were directed by the person being interviewed and not the researcher. FI(CODE) examined each step of the treatment process and identified a number of suboptimal treatment practices. These could be loosely grouped under one of four themes: treatment team communication, patient empowerment, treatment choice, and treatment delivery. These themes are consistent with the results of quantitative rheumatology studies, which have shown that patients often 
have personal preferences in both treatment choices and injection delivery methods [11, 31-34].

Qualitative studies across a range of medical disciplines have reported a need for improved communication about treatment considerations and the importance of patients feeling empowered to have an active role in their disease management [34-37]. Differences in priorities and beliefs between patients and those treating them can lead to misconceptions that directly affect treatment decisions, including the initiation of biologic therapy. Improved communication can support and empower patients to make more informed decisions [34].

IM2020 was designed to focus only on one aspect of the treatment process, self-injection. Using clustering analysis, this study identified five components that influence the success of self-injection: the delivery process, emotional state, social perception, educational level, and ritual development. Social components described in the IM2020 study included a fear of needles and a general negative connotation with the injection experience, which are factors known to affect patients' experiences with self-administration [10].

Patient education was typically provided by HCPs but was limited by factors competing for HCP resources and focused on the mechanics of injection rather than dealing with any emotional aspects that the patient may experience. A number of patients interviewed in FI(CODE) reported that they actively searched for information on their disease and looked for potential alternative therapies to complement their treatment regimen. Without adequate levels of health literacy and guidance from HCPs, patients could access incorrect information, potentially impacting negatively on treatment outcomes. Incorporating specialist patient education services as part of the treatment package soon after diagnosis may help improve patient education, while reducing the burden on HCP resources. Improved patient outcomes have been reported when including patient education as part of the treatment process [36], for example when using a decision tool to inform patients choosing disease-modifying anti-rheumatic drugs [35].
Increasing the number of available treatment devices and patient support services has the potential to improve treatment outcomes, as patients could align their treatment with their personal preferences and specific needs. For example, they could select treatments based on administration routes if they were fearful of self-injection. This study demonstrates that treatment choice is restricted by the patients' healthcare system. New patients were often unaware of this, but more experienced patients who had undergone several treatment cycles routinely commented that there was insufficient treatment choice. However, providing more treatment administration options and support services may not benefit patients without first educating them on the differences between treatments (i.e., subcutaneous vs. intravenous delivery, autoinjector vs. pre-filled syringe), which could lead to a greater burden on HCP time.

Anxiety induced by the process of self-injection and the negative effect this has on patients' lives has been reported elsewhere [38]. FI(CODE) and IM2020 both provided insights into common rituals developed by patients to help them mitigate their fear and anxieties of self-injection. Teaching new patients ritual development techniques when offering self-injection as a treatment option could improve the treatment experience, as patients would not need to rely on a process of trial and error to optimize self-injection. The injection framework developed by IM2020 revealed that a number of components affect the success of self-injection. Considering all aspects of the self-injection moment (i.e., the delivery, emotional, social, educational, and ritual components) when designing a self-injection device has the potential to improve patients' self-injection experience.

There were several limitations associated with this study. All patients had at least 1 year of treatment experience and had been through 1 cycle of treatment failure, which meant no newly diagnosed patient was included in the study. As such, this study relied on patients' recollections of their initial treatment experiences, which is associated with a number of potential limitations, including false memory 
formation and negative bias [39, 40]. The number of patients interviewed was not sufficient to allow meaningful comparisons between subgroups and so it was not possible to assess the influence of geographical regions or different healthcare systems. Finally, although patients were selected to ensure a representative sample of typical patients and HCPs, because of the qualitative nature of the study, generalizing the results to the wider RA and CD population requires caution.

\section{CONCLUSIONS}

The analyses reported here highlight the value of ethnographic research as a means to gain a better understanding of patients' lived experiences of self-injection. Several areas were identified that could be improved to enhance the patient treatment pathway, including the identification of a suitable injection device targeted to the patients' needs, increasing access to educational resources to improve patients' understanding of their disease, and providing guidance to empower patients to develop a personalized self-injection ritual. Optimizing these areas for each patient may help to increase treatment adherence and ultimately improve clinical outcomes for patients taking biologic therapy.

\section{ACKNOWLEDGEMENTS}

UCB sponsored the study, the development of the manuscript, and the article processing charges, and it reviewed the text to ensure that from a UCB perspective, the data presented in the publication are scientifically, technically, and medically supportable, that they do not contain any information that has the potential to damage the intellectual property of UCB, and that the publication complies with applicable laws, regulations, guidelines, and good industry practice. All authors had full access to all of the data in this study and take complete responsibility for the integrity of the data and accuracy of the data analysis. The authors approved the final version to be published after critically revising the manuscript for important intellectual content. All named authors meet the International Committee of Medical Journal Editors (ICMJE) criteria for authorship for this manuscript, take responsibility for the integrity of the work as a whole, and have given final approval to the version to be published. The authors thank the patients and their caregivers in addition to the investigators and their teams who contributed to this study. The authors acknowledge Debbie Nixon, DPhil (UCB Pharma, UK), for publication coordination, and Simon Foulcer, PhD (Costello Medical Consulting Ltd., UK), for medical writing and editorial assistance in preparing this manuscript for publication, based on the authors' input and direction.

Author Contributions. Substantial contributions to study conception/design, or acquisition/analysis/interpretation of data: MS, SS, IM, $\mathrm{PH}$; drafting of publication, or revising it critically for important intellectual content: MS, SS, IM, PH; final approval of the publication: MS, SS, IM, PH.

Disclosures. Michael Schiff: received consulting fees and grant/research support from UCB Pharma. Shane Saunderson: received consulting fees from UCB Pharma. Paul Hartley: received consulting fees from UCB Pharma. Irina Mountian is an employee of UCB Pharma.

Compliance with Ethics Guidelines. All procedures followed were in accordance with the ethical standards of the responsible committee on human experimentation (institutional and national) and with the Helsinki Declaration of 1964, as revised in 2013. Informed consent was obtained from all patients before they were included in the study.

Data Availability. The datasets generated during and/or analyzed during the current study are not publicly available due to confidentiality clauses signed with patients and HCPs, but are available from the corresponding author on reasonable request. 
Open Access. This article is distributed under the terms of the Creative Commons Attribution-NonCommercial 4.0 International License (http://creativecommons.org/licenses/ by-nc/4.0/), which permits any noncommercial use, distribution, and reproduction in any medium, provided you give appropriate credit to the original author(s) and the source, provide a link to the Creative Commons license, and indicate if changes were made.

\section{REFERENCES}

1. El-Gabalawy H, Guenther LC, Bernstein CN. Epidemiology of immune-mediated inflammatory diseases: incidence, prevalence, natural history, and comorbidities. J Rheumatol Suppl. 2010;85:2-10.

2. Singh JA, Saag KG, Bridges SL Jr, Akl EA, Bannuru RR, Sullivan MC, et al. 2015 American College of Rheumatology guideline for the treatment of rheumatoid arthritis. Arthritis Rheumatol (Hoboken, NJ). 2016;68(1):1-26.

3. Tabas I, Glass CK. Anti-inflammatory therapy in chronic disease: challenges and opportunities. Science (New York, NY). 2013;339(6116):166-72.

4. Ford AC, Sandborn WJ, Khan KJ, Hanauer SB, Talley NJ, Moayyedi P. Efficacy of biological therapies in inflammatory bowel disease: systematic review and meta-analysis. Am J Gastroenterol. 2011;106(4):644-59.

5. Southwood TR, Foster HE, Davidson JE, Hyrich KL, Cotter CB, Wedderburn LR, et al. Duration of etanercept treatment and reasons for discontinuation in a cohort of juvenile idiopathic arthritis patients. Rheumatology (Oxford, England). 2011;50(1):189-95.

6. Lopez-Gonzalez R, Leon L, Loza E, Redondo M, Garcia de Yebenes MJ, Carmona L. Adherence to biologic therapies and associated factors in rheumatoid arthritis, spondyloarthritis and psoriatic arthritis: a systematic literature review. Clin Exp Rheumatol. 2015;33(4):559-69.

7. Ganguli A, Clewell J, Shillington AC. The impact of patient support programs on adherence, clinical, humanistic, and economic patient outcomes: a targeted systematic review. Patient Prefer Adherence. 2016;10:711-25.

8. Remington $\mathrm{G}$, Rodriguez $\mathrm{Y}$, Logan D, Williamson C, Treadaway K. Facilitating medication adherence in patients with multiple sclerosis. Int J MS Care. 2013;15(1):36-45.

9. Brod M, Rousculp M, Cameron A. Understanding compliance issues for daily self-injectable treatment in ambulatory care settings. Patient Prefer Adherence. $2008 ; 2: 129-36$.

10. Keininger D, Coteur G. Assessment of self-injection experience in patients with rheumatoid arthritis: psychometric validation of the Self-Injection Assessment Questionnaire (SIAQ). Health Qual Life Outcomes. 2011;9:2.

11. Schwartzman S, Morgan GJ Jr. Does route of administration affect the outcome of TNF antagonist therapy? Arthritis Res Therapy. 2004;6(Suppl 2):S19-23.

12. Cramer JA, Roy A, Burrell A, Fairchild CJ, Fuldeore MJ, Ollendorf DA, et al. Medication compliance and persistence: terminology and definitions. Value Health. 2008;11(1):44-7.

13. World Health Organization. Adherence to long-term therapies: evidence for action. Geneva: WHO; 2003.

14. Carter CT, Waters HC, Smith DB. Impact of infliximab adherence on Crohn's disease-related healthcare utilization and inpatient costs. Adv Ther. 2011;28(8):671-83.

15. Kane SV, Chao J, Mulani PM. Adherence to infliximab maintenance therapy and health care utilization and costs by Crohn's disease patients. Adv Ther. 2009;26(10):936-46.

16. Stein DJ, Ananthakrishnan AN, Issa M, Williams JB, Beaulieu DB, Zadvornova Y, et al. Impact of prior irregular infliximab dosing on performance of long-term infliximab maintenance therapy in Crohn's disease. Inflamm Bowel Dis. 2010;16(7):1173-9.

17. Tang B, Rahman M, Waters HC, Callegari P. Treatment persistence with adalimumab, etanercept, or infliximab in combination with methotrexate and the effects on health care costs in patients with rheumatoid arthritis. Clin Ther. 2008;30(7):1375-84.

18. Savage J. Ethnography and health care. BMJ Br Med J. 2000;321(7273):1400-2.

19. Goodson L, Vassar M. An overview of ethnography in healthcare and medical education research. J Educ Eval Health Prof. 2011;8:4.

20. Geertz C. Thick description: toward an interpretive theory of culture. Read Philos Soc Sci. 1994;213-31. 
21. Morgan-Trimmer S, Wood F. Ethnographic methods for process evaluations of complex health behaviour interventions. Trials. 2016;17(1):232.

22. Ajjawi R, Higgs J. Using hermeneutic phenomenology to investigate how experienced practitioners learn to communicate clinical reasoning. Qual Rep. 2007;12(4):612-38.

23. Lindseth A, Norberg A. A phenomenological hermeneutical method for researching lived experience. Scand J Caring Sci. 2004;18(2):145-53.

24. Bourdieu P. Distinction: a social critique of the judgement of taste. Cambridge: Harvard University Press; 1984.

25. Attride-Stirling J. Thematic networks: an analytic tool for qualitative research. Qual Res. 2001;1(3):385-405.

26. Atkinson P, Hammersley M. Ethnography and participant observation. In: Denzin NK, Lincoln YS, editors. Handbook of qualitative research. Thousand Oaks: Sage; 1994. p. 248-260.

27. Singh JA, Saag KG, Bridges SL, Akl EA, Bannuru RR, Sullivan MC, et al. 2015 American College of Rheumatology guideline for the treatment of rheumatoid arthritis. Arthritis Rheumatol. 2016;68(1):1-26.

28. Billioud V, Laharie D, Filippi J, Roblin X, Oussalah A, Chevaux JB, et al. Adherence to adalimumab therapy in Crohn's disease: a French multicenter experience. Inflamm Bowel Dis. 2011;17(1):152-9.

29. Fair BS. Contrasts in patients' and providers' explanations of rheumatoid arthritis. J Nurs Scholarsh. 2003;35(4):339-44.

30. Potkin S, Bera R, Zubek D, Lau G. Patient and prescriber perspectives on long-acting injectable (LAI) antipsychotics and analysis of in-office discussion regarding LAI treatment for schizophrenia. BMC Psychiatry. 2013;13:261.

31. Sheikhzadeh A, Yoon J, Formosa D, Domanska B, Morgan D, Schiff M. The effect of a new syringe design on the ability of rheumatoid arthritis patients to inject a biological medication. Appl Ergon. 2012;43(2):368-75.
32. Domanska B, VanLunen B, Peterson L, Mountian I, Schiff M. Comparative usability study for a certolizumab pegol autoinjection device in patients with rheumatoid arthritis. Expert Opin Drug Deliv. 2017;14(1):15-22.

33. Hazlewood GS, Bombardier C, Tomlinson G, Thorne C, Bykerk VP, Thompson A, et al. Treatment preferences of patients with early rheumatoid arthritis: a discrete-choice experiment. Rheumatology (Oxford, England). 2016;55(11):1959-68.

34. Bolge SC, Goren A, Brown D, Ginsberg S, Allen I. Openness to and preference for attributes of biologic therapy prior to initiation among patients with rheumatoid arthritis: patient and rheumatologist perspectives and implications for decision making. Patient Prefer Adherence. 2016;10:1079-90.

35. Nota I, Drossaert CH, Taal E, Vonkeman HE, Haagsma CJ, van de Laar MA. Evaluation of a patient decision aid for initiating disease modifying anti-rheumatic drugs. Arthritis Res Therapy. 2016;18(1):252.

36. Voshaar MJ, Nota I, van de Laar MA, van den Bemt BJ. Patient-centred care in established rheumatoid arthritis. Best Pract Res Clin Rheumatol. 2015;29(4-5):643-63.

37. Hifinger M, Hiligsmann M, Ramiro S, Severens JL, Fautrel B, Watson V, et al. Patients' preferences and economic considerations play an important role in treatment decisions: a discrete choice experiment among rheumatologists. Rheumatology (Oxford, England). 2017;56(1):68-76.

38. Cox D, Stone J. Managing self-injection difficulties in patients with relapsing-remitting multiple sclerosis. J Neurosci Nurs. 2006;38(3):167-71.

39. Baumeister RF, Bratslavsky E, Finkenauer C, Vohs $\mathrm{KD}$. Bad is stronger than good. Rev General Psychol. 2001;5(4):323.

40. Loftus EF, Pickrell JE. The formation of false memories. Psychiatr Ann. 1995;25(12):720-5. 